\title{
PENGGUNAAN MEDIA JARUM BERGOYANG DALAM MATERI MEDAN MAGNET UNTUK MENINGKATKAN PEMAHAMAN KONSEP PESERTA DIDIK
}

\author{
BUDI HENDRATNO \\ Pascasarjana PMIPA, Universitas Indraprasta PGRI, Jakarta \\ e-mail : budihendratno71@gmail.com
}

\begin{abstract}
ABSTRAK
Tujuan dari penulisan ini adalah untuk lebih meningkatkan pemahaman siswa terhadap konsep medan magnet, dengan membuat media yang dapat menunjukan karakteristik medan magnet, yang merupakan besaran yang bersifat abstrak dan besaran vektor. Media ini dirancang selain bisa membuktikan keberadaan medan magnet yang bersifat abstrak, juga dapat menunjukan arah garis-garis gaya magnet, menunjukan bentuk lintasan lengkung garis-garis gaya magnet, dan bisa secara langsung menentukan kutub-kutub magnet apabila magnetnya itu dibuat dengan cara elektromagnetik. Sementara media yang sering dipakai selama ini hanya dapat membuktikan keberadaannya saja. Proses pembuatan media ini melalui tiga tahapan yaitu ; merancang, merakit dan menguji. Media ini dirancang dengan menggunakan jarum yang ditempatkan di atas air dan didekatkan dengan magnet dengan istilah media jarum bergoyang. Proses perakitan menggunakan alat yang sederhana dan bahan yang mudah didapat. Proses pengujian dilakukan pada kegiatan praktikum kemagnetan oleh siswa kelas IX-C SMP Negeri 2 Saketi Tahun 2015. Hasil praktikum dapat disimpulkan bahwa media jarum bergoyang dapat digunakan untuk membuktikan adanya medan magnet, dapat menentukan arah garis-garis gaya magnet, dapat menunjukan bentuk lintasan garis-garis gaya magnet dan dapat secara langsung menunjukan kutub-kutub magnet kumparan.
\end{abstract}

Kata kunci: Media Pembelajaran, Medan Magnet, Konsep IPA

\section{ABSTRACT}

The purpose of this paper is to further improve students' understanding of the concept of magnetic fields, by creating media that can show the characteristics of magnetic fields, which are abstract quantities and vector quantities. This media is designed in addition to being able to prove the existence of an abstract magnetic field, it can also show the direction of the magnetic lines of force, show the shape of the curved trajectory of the magnetic lines of force, and can directly determine the magnetic poles if the magnet is made by electromagnetic means. While the media that is often used so far can only prove its existence. The process of making this media through three stages, namely; design, assemble and test. This media is designed by using a needle that is placed above the water and brought close to a magnet with the media term "Jarum Bergoyang". The assembly process uses simple tools and easily available materials. The testing process was carried out on magnetic practicum activities by class IX-C students of SMP Negeri 2 Saketi 2015. The results of the practicum can be concluded that swaying needle media can be used to prove the existence of a magnetic field, can determine the direction of magnetic force lines, can show the shape of the line trajectory. magnetic lines of force and can directly show the magnetic poles of the coil.

Keywords: Learning Media, Magnetic Field, Science Concept

\section{PENDAHULUAN}

Pembelajaran di dalam kelas, pada dasarnya dimaksudkan untuk membantu siswa bertahan hidup atau bahkan mewarnai kehidupan. Karena itu, pembelajaran di sekolah tidak seharusnya diarahkan untuk sekedar mengenal, mengingat, atau memahami ilmu pengetahuan. Siswa harus mampu memanfaatkan ilmu pengetahuan yang dipelajarinya untuk bekal mereka dalam mengenali dan mengatasi masalah kehidupan atau bahkan dalam menciptakan sesuatu yang bermanfaat bagi kehidupan (Prioritas, 2013:216). 
IPA Fisika adalah suatu ilmu yang lebih banyak memerlukan pemahaman daripada hafalan. Kunci kesuksesan siswa dalam memahami konsep-konsep (pengertian), hukum-hukum atau azas-azas dan teori-teori, dapat ditunjukan oleh kemampuan siswa menerapkan tiga hal pokok tersebut (Kertiasa, 1993).

Seperti kita ketahui, konsep IPA Fisika mempunyai tingkat generalisasi dan keabstrakan yang tinggi, sehingga tingkat penguasaan siswa terhadap pelajaran sangat lemah. Masalah utama yang sering terjadi dalam pengajaran IPA Fisika adalah kesulitan siswa dalam memahami dan menguasai materi pelajaran, yang tercermin ketidakmampuan mereka dalam memecahkan masalah-masalah IPA.

Permasalahan di lapangan yang timbul berdasarkan pengamatan dan pemantau, terhadap kemampuan peserta didik di dalam memecahkan soal Ujian Nasional IPA Praktik Tahun 2014. Secara umum mereka tidak mampu menjelaskan prinsip kerja sebuah kompas. Prinsip kerja kompas adalah, adanya interaksi antara medan magnet kompas dengan medan magnet yang dihasilkan oleh kemagnetan Bumi. Padahal konsep medan magnet ini harus betulbetul dipahami karakteristiknya. Konsep medan magnet merupakan dasar untuk memahami konsep induksi elektromagnetik, yang penerapanya digunakan untuk alat bantu dalam kehidupan sehari hari yang menggunakan motor listrik. Alat yang menggunakan motor listrik contohnya pompa air, serutan kayu, kipas angin, mesin cuci dan lain lain. Alat-alat tersebut bekerja memanfaatkan efek magnetik, akibat medan magnet pada motor listrik, dapat mengubah energi listrik menjadi energi mekanik. Hampir setiap hari kita menggunakan energi mekanik yang dihasilkan dari induksi elektromagnetik.

Medan magnet merupakan besaran vektor selain memiliki nilai juga memiliki arah. Medan magnet tidak dapat kita lihat secara langsung, tetapi keberadaanya bisa dibuktikan. Untuk membuktikan adanya medan magnet, yang dilukiskan dengan garis-garis gaya magnet, yang memiliki arah dari kutub Utara menuju kutub Selatan, dan lintasanya berupa garis lengkung, maka perlu dibuat alat untuk menunjukan hal tersebut. Banyak media yang bisa membuktikan hal tersebut, salah satu diantaranya dengan menggunakan serbuk besi yang ditaburkan di atas kertas yang dibawahnya ada magnet batang. Menurut penulis media tersebut masih banyak kekurangannya, diantaranya; pertama media ini hanya bisa membuktikan keberadaan medan magnet, tetapi tidak bisa menunjukan arah garis-garis gaya magnet, ke-dua tidak bisa menunjukan bentuk lintasan lengkung garis-garis gaya magnet dan ketiga tidak bisa secara langsung menentukan kutub-kutub magnet apabila magnetnya itu dibuat dari kumparan yang dialiri arus listrik (elektromagnetik). Akibat menggunakan media serbuk besi maka, pemaham siswa terhadap konsep medan magnet masih belum lengkap.

Berdasarkan permasalahan di atas, maka penulis mencoba untuk membuat media dengan menggunakan jarum yang ditempatkan di atas air dan didekatkan dengan magnet dengan istilah " Media jarum bergoyang ". Alat ini dipergunakan sebagai media dalam pembelajaran IPA, khususnya untuk menjelaskan konsep medan magnet di kelas IX semester genap di SMP/ MTs. Tujuan pembuatan media ini untuk membantu agar siswa lebih memahami karakteristik medan magnet, sehingga siswa mampu menyelesaikan permasalahan di dalam kehidupannya.

\section{METODE PENELITIAN}

Metode penelitian yang dipergunakan adalah metode penelitian deskriptif, karena data mula-mula disusun, dijelaskan dan kemudian dianalisis, sesuai dengan pendapat yang dikemukakan oleh (Surakhmad (1990:140). Data yang diperlukan dalam penelitian ini langsung dikumpulkan dari siswa. Data tersebut merupakan data primer, yaitu data yang langsung dan segera diperoleh dari sumber data oleh peneliti, untuk tujuan yang khas (Surakhmad (1990:163).

Melalui pengelolaan data dan analisis data dibuat deskripsi untuk sampai pada kesimpulan.

Tiga tahap dalam proses penelitian ini, yaitu : 
1. Proses Merancang Media

Rancangan media harus dibuat agar alat yang akan dibuat dapat menunjukan karakteristik medan magnet lebih lengkap, mudah dibuat, mudah digunakan dan menyenangkan. Media jarum bergoyang digunakan untuk menjawab tuntutan tersebut. Berdasarkan masalah di atas, maka dirancanglah gambar media sebagai berikut :

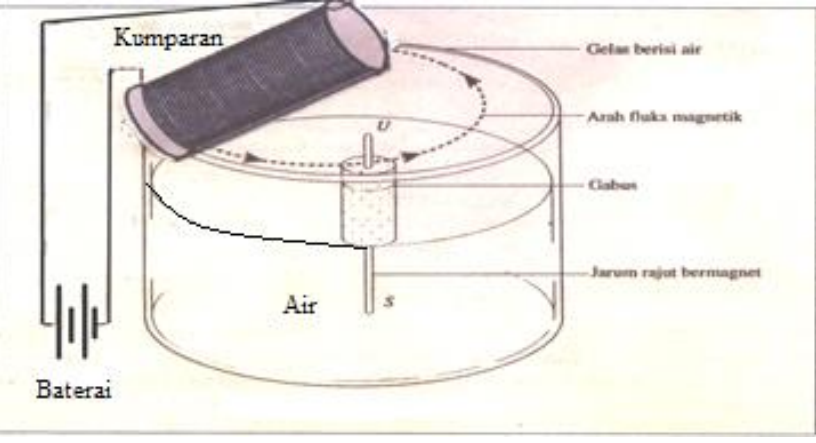

\section{Gambar 1. Rancangan Media Jarum Bergoyang}

2. Proses Merangkai Media

Gambar di bawah ini merupakan media jarum bergoyang. Nama jarum bergoyang karena dengan melihat karakteristik jarum yang selalu bergoyang pada saat jarum tersebut bergerak untuk menunjukan arah, dan bentuk medan magnet. Secara lengkap alat ini digunakan untuk menunjukan medan magnet, arah garis gaya magnet dan menentukan kutub-kutub magnet kumparan.

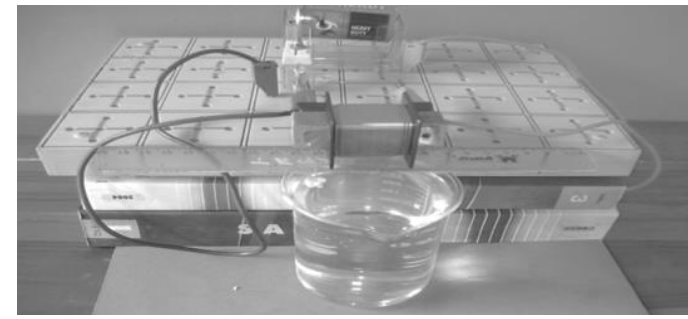

Gambar 2. Foto Media Jarum Bergoyang

Alat dan bahan yang dipergunakan

Tabel 1. Alat dan Bahan

\begin{tabular}{|c|l|c|}
\hline No. & Nama Alat & Jumlah \\
\hline 1. & Papan Rangkaian. & 1 buah \\
2. & Gelas Kaca atau Baskom Plastik. & 1 buah \\
3. & Air. & $250 \mathrm{ml}$ \\
4. & Gabus atau Busa Styrofoam. & 1 buah \\
5. & Jarum Jahit. & 1 buah \\
6. & Sumber Tegangan (Power Supply) & 1 buah \\
7. & Dudukan Baterai. & 1 buah \\
8. & Saklar. & 1 buah \\
9. & Kabel. & 1 meter \\
10. & Magnet Batang. & 1 buah \\
11. & Kumparan 500 lt & 1 buah \\
12. & Besi Lunak. & 1 buah \\
13. & Mistar & 1 buah \\
14. & Pisau Cutter. & 1 buah \\
\hline
\end{tabular}

3. Proses Penggunaan Media

Langkah- langkah penggunaan media sebagai berikut :

1. Rangkailah alat dan bahan seperti gambar-2 di atas.

2. Isilah gelas dengan air sebanyak $250 \mathrm{ml}$.

3. Dengan bantuan mistar sebagai penyangga, letakkan kumparan dipinggir gelas, upayakan dipinggir bagian tengah.

4. Gosoklah jarum dengan magnet batang, sampai jadi magnet jarum. 
5. Tentukan kutub-kutub magnet jarum yang baru dibuat dengan cara disimpan di permukaan air, tetapi jangan sampai tenggelam (terapung) dengan bantuan busa, tunggu beberapa saat sampai jarum itu menyimpang ke arah Utara dan Selatan. Beritanda masing-masing kutubnya sesuai dengan arah penyimpangannya, pada bagian pangkal atau ujung jarum.

6. Buatlah pelampung dari busa dengan diameter $1 \mathrm{~cm}$ menggunakan cutter, kemudian tusukkan sebagian magnet jarum ke dalam gabus atau busa pas ditengah-tengahnya.

7. Masukkan jarum ke dalam gelas yang telah diisi air.

8. Hubungkan kumparan dengan sumber tegangan (Baterai).

9. Kontakan saklar.

10. Perhatikan arah dan bentuk lintasan pergerakan jarum.

11. Matikan saklar.

12. Balikkan posisi kutub baterai, kutub + menjadi - atau sebaliknya.

13. Kontakan saklar.

14. Perhatikan arah dan bentuk lintasan pergerakan jarum.

15. Catat hasil pengamatan di laporan hasil praktikum.

Ulangi percobaan tersebut berurutan beberapa kali, dengan menggunakan magnet

kumparan dan tegangan yang berbeda.

4. Proses Pengujian Media

Proses pengujian dilakukan pada proses pembelajaran materi kemagnetan di Kelas IX-C Tahun pelajaran 2014/2015. Kegiatan yang dilakukan yaitu :

1. Menyusun Rencana Pelaksanaan Pembelajaran.

2. Melakukan Penilaian.

3. Menganalisis hasil Praktikum.

Data yang digunakan untuk dianalisis adalah hasil ulangan, laporan praktikum, dan pengamatan langsung penulis berupa Video. .

5. Melakukan Desiminasi.

Desiminasi dilakukan melalui seminar yang dilaksanakan di MGMP IPA SMP Kabupaten Pandeglang.

\section{HASIL DAN PEMBAHASAN}

Hasil

Berdasarkan hasil observasi oleh observer tentang keefektifan media pada saat proses pembelajaran berlangsung, didapat data sebagai berikut :

Tabel 3. Hasil Observasi Keefektifan Media

\begin{tabular}{clc}
\hline No. & Observer & Skor \\
\hline 1. & Observer I & 19 \\
2. & Observer II & 20 \\
3. & Observer III & 19 \\
4. & Observer IV & 19 \\
\hline & Jumlah skor & 77 \\
\hline & Persentase & 91,67 \\
\hline
\end{tabular}

Hasil observasi keefektifan media adalah 97,67 \%, ini memberikan gambaran bahwa peserta didik mengalami dinamika dan peningkatan proses pembelajaran yang mampu memberdayakan kemampuan penguasaan konsep medan magnet. Ini dikarenakan adanya perpaduan dua unsur yaitu penggunaan media pembelajaran yang mampu membantu peserta didik lebih aktif dalam proses pembelajaran dan membantu memahami konsep medan magnet baik oleh guru maupun oleh peserta didik, sehingga menimbulkan fokus dan motivasi bagi siswa untuk lebih tertarik belajar dengan aktif dan siswa interaktif dalam kelompok . Hal di atas membuktikan bahwa melalui penggunaan media pembelajaran yang sesuai akan meningkatkan kualitas proses pembelajaran dan akan membuahkan hasil yang optimal melalui upaya yang maksimal. 
Berdasarkan pengamatan dan pemantau terhadap kemampuan peserta didik memecahkan soal Ujian Nasional IPA Praktik Tahun 2014, sebelum penggunaan media jarum bergoyang diterapkan, secara umum mereka tidak mampu menjelaskan prinsip kerja sebuah kompas, dan prinsip kerja motor listrik, yang tercermin dari rendahnya nilai Ujian Nasional praktik tersebut. Hal ini terjadi karena mereka belum menguasai konsep medan magnet. Menyimpangnya jarum kompas menuju ke arah utara dan selatan, terjadi karena adanya interaksi antara medan magnet Bumi dengan medan magnet jarum kompas. Medan magnet yang digambarkan berupa garis-garis gaya magnet yang dihasilkan oleh medan magnet Bumi dengan medan magnet jarum kompas akan saling mempengaruhi, karena garis garis gaya magnet memiliki arah maka disini ada interaksi dua besaran vektor. Hal yang sama terjadi pada prinsip kerja motor listrik. Rotor motor listrik bisa berputar akibat adanya gaya magnet, yang timbul akibat adanya interaksi antara arus listrik dengan medan magnet. Arah putaran rotor pada motor listrik bisa berubah berlawanan arah, jika arah arus diubah atau arah medan magnetnya dirubah. Dari masalah di atas hal ini terjadi, karena siswa tidak paham bahwa sebenarnya medan magnet itu memiliki arah. Dengan menggunakan media jarum bergoyang dapat membantu siswa memahami bahwa medan magnet adalah besaran selain memiliki nilai juga memiliki arah, yang tidak dapat dijelaskan dengan media sebelumnya.

Berdasarkan hasil observasi data hasil penilaian tes uraian, dan laporan hasil praktikum diakhir pelajaran setelah menggunakan media jarum bergoyang, diperoleh hasil sebagai berikut
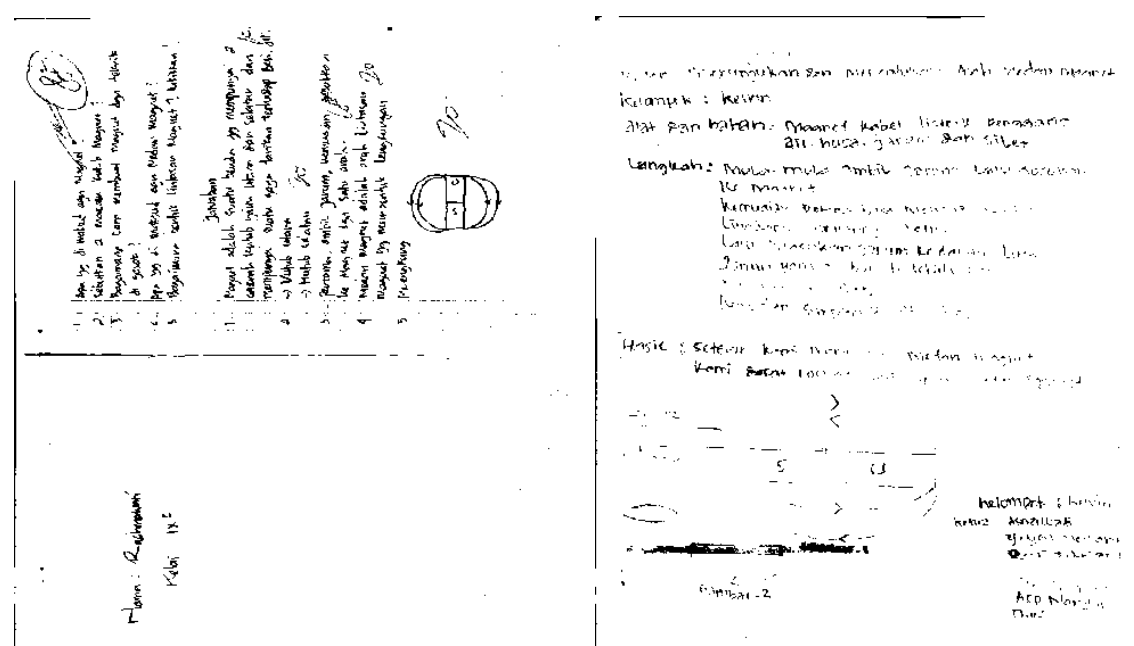

Gambar 3. Hasil Penilaian Tes Uraian

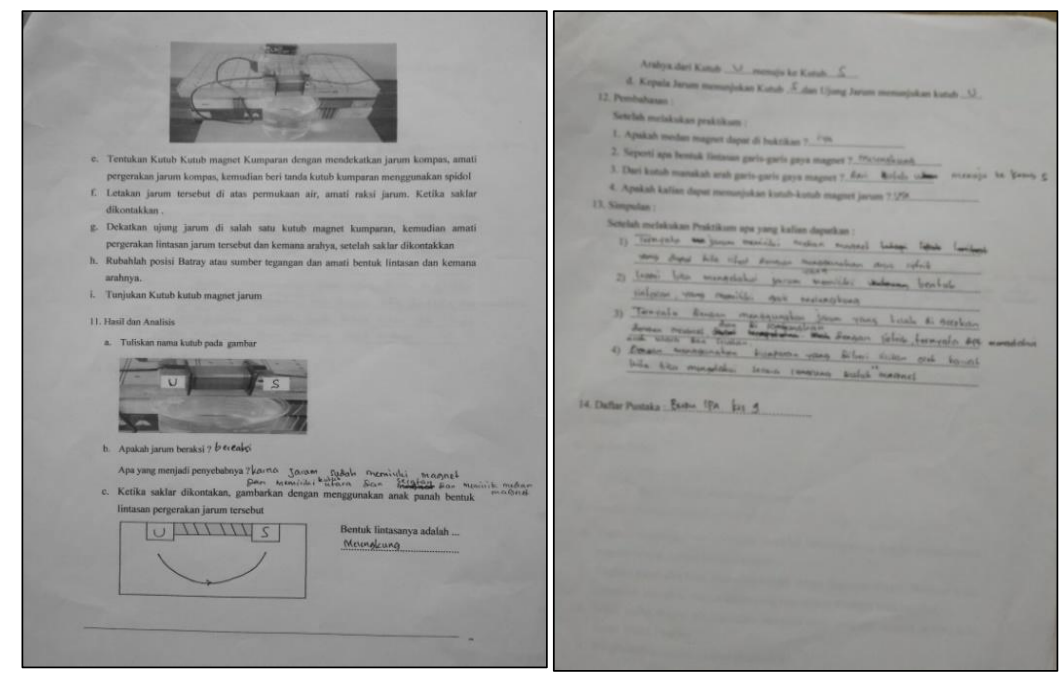

Gambar 4. Laporan Praktikum Siswa 


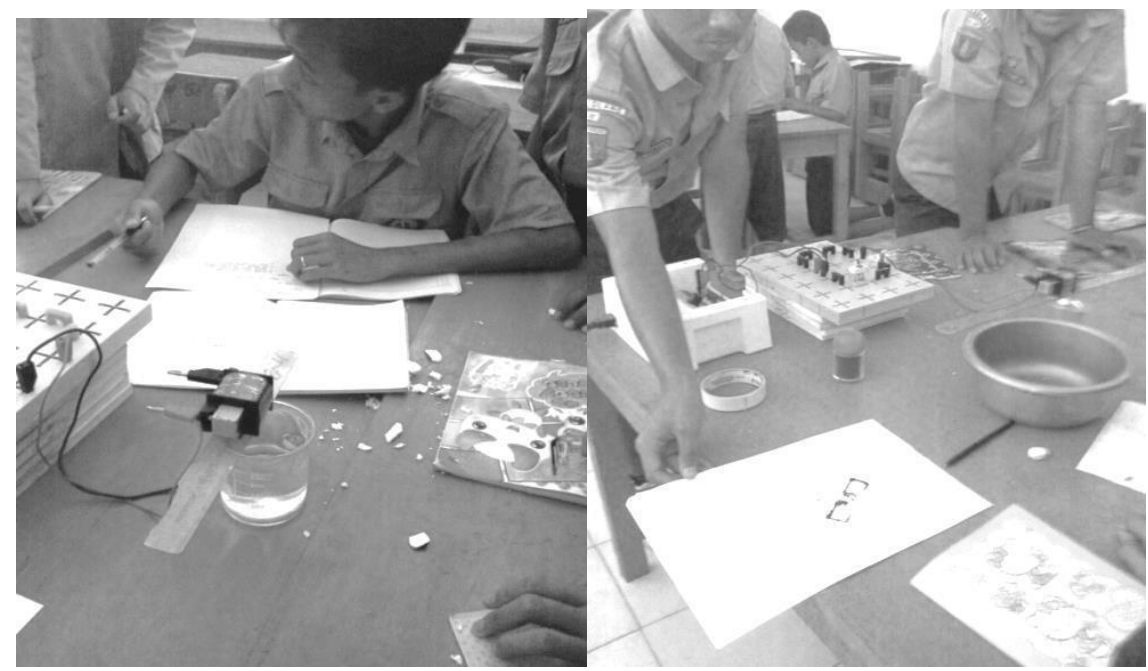

Gambar 5. Kegiatan Praktikum

Dari data di atas dapat dianalisis bahwa, media jarum bergoyang dapat digunakan untuk membuktikan :

1. Di sekitar kumparan terdapat medan magnet. Hal itu dibuktikan bahwa, apabila jarum tersebut disimpan di permukaan air, jarum tersebut akan bereaksi, menjauh dan mendekat. Hal tersebut membuktikan, adanya medan magnet di sekitar kumparan.

2. Jarum bergerak membentuk lintasan melengkung / setengah lonjong yang arahnya dari kutub Utara menuju kutub Selatan Magnet. Hal tersebut membuktikan, media ini dapat menunjukan arah garis-garis gaya magnet.

3. Jarum bergerak membentuk lintasan melengkung / setengah lonjong dari kutub-kutub Magnet. Hal tersebut membuktikan, bentuk lintasan garis-garis gaya magnet.

4. Dengan menggunakan sifat-sifat magnet, yaitu :

- Kutub-kutub senama jika didekatkan akan tolak menolak.

- Kutub-kutub yang tidak senama jika didekatkan akan tarik menarik.

Kita bisa menentukan nama kutub-kutubnya, dengan mendekatkan jarum. Jika jarum menjauh maka dipastikan kutub kumparan tersebut sejenis, dan sebaliknya bila jarum mendekat dikatakan kutub kumparan tersebut tidak sejenis. Hal tersebut membuktikan, bahwa media ini dapat secara langsung menentukan kutub-kutub magnet kumparan.

\section{Pembahasan}

Garis medan magnetik seperti garis medan listrik bersifat khayal. Garis-garis medan magnetik selain membantu menggambarkan arah medan magnet, juga membantu menggambarkan besar kuat medan. Disepakati arah garis medan magnetik di luar magnet, keluar dari kutub utara magnet dan masuk ke kutub selatan magnet (Depdiknas, 2004).

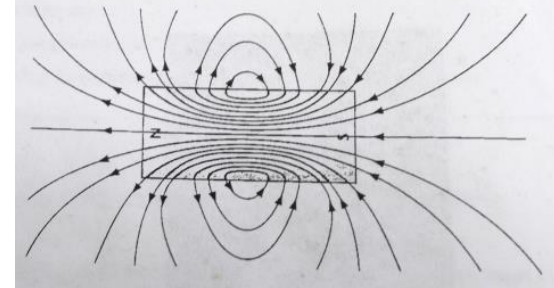

\section{Gambar 6. Garis-Garis Gaya Magnet}

Untuk Membuktikan adanya medan magnet yang dilukiskan dengan garis-garis gaya magnet yang memiliki arah dan lintasanya berupa garis lengkung, maka perlu dibuat alat untuk menunjukan hal itu. Banyak media yang bisa membuktikan hal tersebut. Salah satu diantaranya dengan menggunakan serbuk besi yang ditaburkan di atas kertas yang dibawahnya ada magnet batang. Timbulnya medan magnetik di sekitar magnet dapat ditunjukan dengan bantuan serbuk besi. Setiap serbuk yang ditaburkan di sekitar magnet akan menjadi sebuah magnet kecil dengan cara induksi dan berkelakuan seperti kompas kecil, berputar sampai kedudukannya sejajar dengan medan magnetik di titik tersebut (Depdiknas, 2004). 

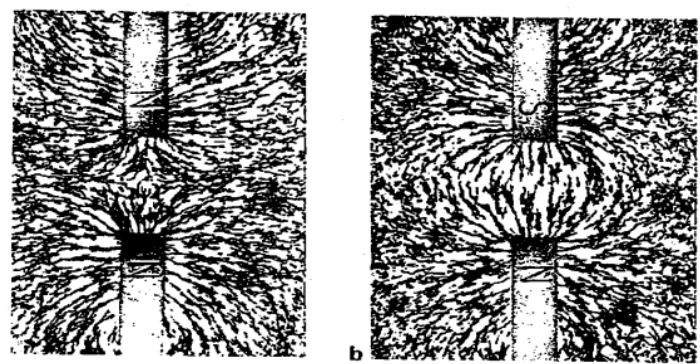

Gambar 7. Medan Magnet Permanen

Menurut penulis media yang digambarkan pada gambar-7, masih banyak kekurangannya, diantaranya:

1. Media ini hanya bisa membuktikan adanya medan magnet, tetapi tidak bisa menunjukan arah garis-garis gaya magnet.

2. Tidak dapat menunjukan bentuk lintasan lengkung garis-garis gaya magnet.

3. Tidak dapat secara langsung menentukan kutub-kutub magnet apabila magnetnya itu dibuat dari kumparan yang diberi arus listrik (elektromagnetik).

Berdasarkan pernyataan di atas, maka rancangan media harus mampu :

1. Membuktikan keberadaan medan magnet.

2. Menunjukan arah medan magnet atau garis-garis gaya magnet dari kutub Utara menuju kutub Selatan di luar magnet.

3. Menunjukan bentuk lintasan melengkung garis-garis gaya magnet.

4. Menunjukan jenis kutub-kutub magnet secara langsung jika magnet terbuat dari kumparan yang diberi arus listrik (elektromagnetik).

Rancangan Media seperti pada gambar-8 di bawah ini menunjukan sebuah magnet batang yang terletak di tepi gelas berisi air. Sebuah jarum yang telah dimagnetkan dipasang pada gabus, kemudian diapungkan dalam air dengan kutub Utara diatasnya. Bila jarum diletakkan dekat kutub Utara magnet, kemudian dilepas, maka jarum akan ditolak dan bergerak ke arah kutub S berupa lintasan yang menggambarkan arah garis-garis gaya magnetik. Apabila percobaan diulangi lagi dengan Kutub Selatan jarum berada di atas, maka jarum akan bergerak dalam arah yang berlawanan.

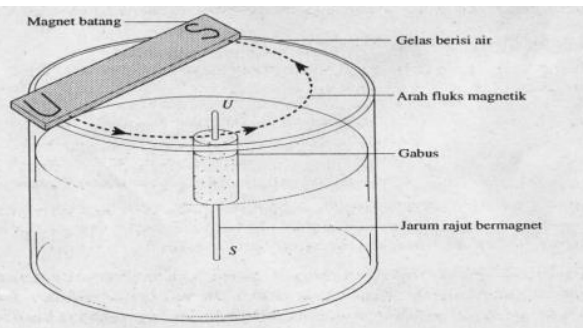

\section{Gambar 8. Lintasan Garis-Garis Gaya Magnet}

Pada saat magnet jarum tersebut ditolak menjauh menuju kutub yang lainnya, kita bisa mengamati bentuk lintasan garis gaya magnetnya karena jarumnya berada di atas permukaan air. Dengan menukarkan posisi kutub + dan - pada sumber tegangan, maka kita akan mengetahui arah pergerakan garis-garis gaya magnet yaitu dari kutub Utara menuju kutub Selatan.

Ketika arus listrik mengalir dalam sebuah kumparan, kumparan menimbulkan medan magnet induksi, seperti sebuah magnet permanen. Jika kumparan berarus listrik dibawa ke sebuah magnet yang terbuat dari jarum yang dimasukkan ke dalam busa styrofoam yang simpan di atas permukaan air, sebuah ujung dari kumparan akan terdorong atau menolak kutub utara magnet. Berdasarkan pernyataan di atas kita bisa menentukan kutub-kutub magnet, dari magnet yang belum diketahui. Sebagai pembanding apakah kutub-kutub magnet tersebut sesuai atau tidak kita menggunakan aturan atau kaidah tangan kanan. 


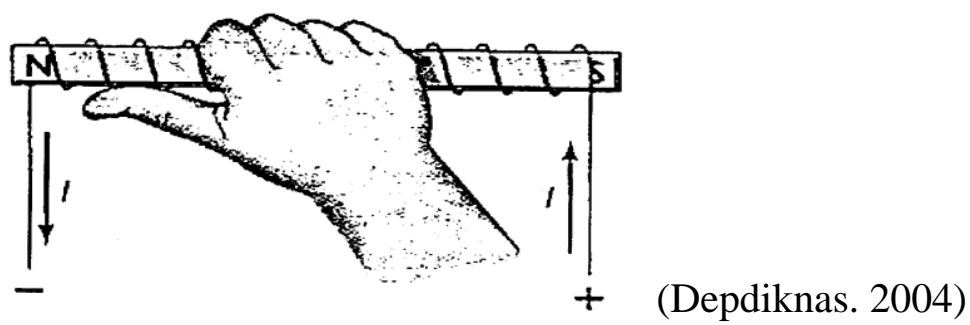

Gambar 9. Aturan Tangan Kanan

Berdasarkan uraian di atas setelah menggunakan media jarum bergoyang di dalam proses pembelajaran,ternyata dari hasil ulangan harian dan laporan hasil praktikum siswa lebih memahami karakteristik medan magnet, sehingga mereka dapat menjelaskan prinsip kerja kompas dan motor listrik.

Media pembelajaran alternatif untuk menganalisis besaran medan magnet yang diakibatkan oleh kawat loop melingkar berarus pada materi medan magnet KD 3.6 dan 4.6 kurikulum 2013. adalah sebagai berikut:

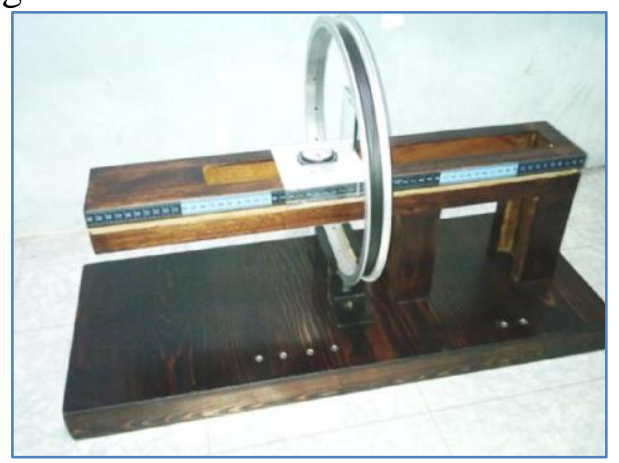

\section{Gambar 10. Alat Praktikum Medan Magnet pada Loop Kawat Berarus}

Media yang dikembangkan berupa alat praktikum medan magnet beserta lembar kerja siswa penunjang praktikum yang telah divalidasi oleh ahli materi, ahli media, dan guru fisika dengan interpretasi sangat baik, dan telah diujicobakan kepada siswa SMA dengan hasil uji coba yang sangat baik. Desain pengembangan media pembelajaran pada materi medan magnet ini dibuat dengan mempertimbangkan kompetensi dasar KD 3.6 dan 4.6 kurikulum 2013 sesuai dengan kompetensi dasar ranah pengetahuan siswa diharapkan mampu mengamati induksi magnet dan gaya magnet disekitar kawat berarus. (Anugrah, Serevina, \& Nasbey, 2015)

Garis-garis gaya magnet tidak pernah saling berpotongan dan selalu keluar dari kutub utara magnet kemudian masuk ke kutub selatan magnet dan berdasarkan hasil pengembangan media pembelajaran alternatif untuk menganalisis besaran medan magnet yang diakibatkan oleh kawat loop melingkar berarus pada materi medan magnet siswa mampu mengamati induksi magnet dan gaya magnet disekitar kawat berarus. Induksi magnet dan gaya magnet yang merupakan karakteristik medan magnet yang bersifat abstrak, tetapi keberadaannya dapat dibuktikan. Berdasarkan pernyataan di atas maka menurut penulis bahwa karakteristik medan magnet selain menggunakan media di atas juga bisa dibuktikan dengan menggunakan media jarum bergoyang.

\section{KESIMPULAN}

Jika dibandingkan dengan media sebelumnya, yaitu menerangkan konsep medan magnet dengan cara menaburkan serbuk besi di atas magnet batang, menurut hasil analisis data berupa hasil ulangan dan laporan praktikum setelah menggunakan media jarum bergoyang lebih efektif karena :

1. Lebih mampu meningkatkan pemaham konsep medan magnet.

2. Lebih banyak karakteristik medan magnet dibandingkan dengan media sebelumnya. Kelebihan Media Jarum bergoyang adalah sebagai berikut :

a) Membuktikan adanya medan magnet di sekitar kumparan. 
b) Dapat menunjukan arah garis-garis gaya magnet.

c) Dapat menunjukan bentuk lintasan garis-garis gaya magnet.

d) Dapat secara langsung menentukan kutub-kutub magnet kumparan.

\section{DAFTAR PUSTAKA}

Anugrah, Muhamad Ivan., Serevina, Vina., Nasbey, Hadi. (2015). Pengembangan Alat Praktikum Medan Magnet Sebagai Media Pembelajaran Fisika SMA, Prosiding Seminar Nasional Fisika (E-Journal) SNF2015 , http://snf-unj.ac.id/kumpulanprosiding/snf2015/.

Dirjendikdasmen Depdiknas. (2004). Media Pembelajaran. Dalam Materi Pelatihan Terintegrasi Ilmu Pengetahuan Alam.Buku 3, Jakarta : Direktorat PLP Dirjen Dikdasmen Depdiknas.

Dirjendikdasmen Depdiknas. (2004). Penulisan Karya Ilmiah. Dalam Materi Pelatihan Terintegrasi Ilmu Pengetahuan Alam.Buku 4, Jakarta : Direktorat PLP Dirjen Dikdasmen Depdiknas.

Mangunwiyoto, Widagdo., Harjono. (1997). Pokok-Pokok Fisika SLTP Jilid 3 , Jakarta : Erlangga.

Kertiasa, Nyoman. (1993). Fisika 1 untuk Sekolah Menengah Umum (SMU) Kelas 1. Jakarta: Depdikbud.

Makmun, Abin Syamsudin. (1995). Psikologi Kependidikan, Bandung : Institut Keguruan dan Ilmu Pendidikan (IKIP) Bandung.

Mariono, Suklis.,\& Yani Muharomah. (2008). Mari Belajar Ilmu Alam Sekitar Panduan Belajar IPA Terpadu Untuk Kelas IX SMP/MTs, Jakarta : Pusat Perbukuan.

Pudak Scientific. (2011). Panduan Contoh-contoh Percobaan Hidrostatika \& Panas Untuk SMP, MTs, dan Sekolah yang sederajat, Bandung : Pudak Scientific.

Saragih, Lasma Rosinta. (2011). Penggunaan Media Potongan Gambar Dalam Model Pembelajaran Kooperatif Tipe Picture And Picture Untuk Meningkatkan Proses Pembelajaran Dan Penguasaan Konsep Organisasi Kehidupan, Skripsi. Sekolah Menengah Pertama Negeri 1 Kepahiang. Kepahiang.

Sugiyarto, Teguh., \& Eny Ismawati. (2008). Ilmu Pengetahuan Alam Untuk SMP/MTs Kelas $I X$, Jakarta : Pusat Perbukuan.

Sulipan. (2011).Sistematika Laporan Kegiatan Pengembangan Keprofesian Berkelanjutan, ppt

Surakhmad, Winarno. (1990). Pengantar Penelitian Ilmiah Dasar Metodik dan Teknik, Bandung: Tarsito .

Usaid Prioritas. (2014).Praktik yang Baik di Sekolah Menengah Pertama dan Madrasah Tsanawiyah (SMP/MTs) II, Serang : Usaid Prioritas.

Usaid Prioritas. (2013).Praktik yang Baik di Sekolah Menengah Pertama dan Madrasah Tsanawiyah (SMP/MTs) I, Serang : Usaid Prioritas. 